Meta

Journal des traducteurs

Translators' Journal

\title{
Il y a de la marge !
}

\section{Paul A. Horguelin}

Volume 12, numéro 3, septembre 1967

URI : https://id.erudit.org/iderudit/003095ar

DOI : https://doi.org/10.7202/003095ar

Aller au sommaire du numéro

Éditeur(s)

Les Presses de l'Université de Montréal

\section{ISSN}

0026-0452 (imprimé)

1492-1421 (numérique)

Découvrir la revue

Citer ce document

Horguelin, P. A. (1967). Il y a de la marge ! Meta, 12(3), 92-93.

https://doi.org/10.7202/003095ar

Ce document est protégé par la loi sur le droit d'auteur. L'utilisation des services d'Érudit (y compris la reproduction) est assujettie à sa politique d'utilisation que vous pouvez consulter en ligne.

https://apropos.erudit.org/fr/usagers/politique-dutilisation/
Cet article est diffusé et préservé par Érudit.

Érudit est un consortium interuniversitaire sans but lucratif composé de l’Université de Montréal, l'Université Laval et l'Université du Québec à Montréal. Il a pour mission la promotion et la valorisation de la recherche. https://www.erudit.org/fr/ 


\section{IL Y A DE LA MARGE!}

Un groupe de traducteurs montréalais, voulant sans doute apporter leur contribution à l'étude de la notion de "marge ${ }^{1}$, se sont livrés au petit exercice de la traduction successive. Voici le résultat de leurs « recherches ».

«Ainsi, ils s'aveuglaient eux-mêmes avec l'impalpable et titillante poudre du détail, comme avec du tabac à priser. »

(Edgar Allan Poe)

So they were losing contact with reality because of an over-indulgence in fluid and exhilarating details, as one does momentarily after taking snuff.

Ainsi, ils perdaient contact avec la réalité en raison de trop généreuses libations et d'autres petites choses hilarantes, comme s'ils avaient prisé du tabac.

Over-indulging in wine and otherwise frolicking, they were thus drifting from reality just as if they had taken snuff.

L'abus du vin et d'autres divertissements les emportaient loin de la réalité, comme s'ils avaient prisé du tabac.

Over-indulgence in wine and other pleasures was carrying them away from reality, as if they had snuffed.

Par suite d'un abandon complet aux plaisirs œnoliques et sensuels, ils oubliaient totalement la réalité tout comme après un long usage du tabac à priser.

Following a complete surrender to wine and sensual pleasures, they forgot all reality as after a long use of snuff.

1. J.-P. Vinay et J. Darbelnet, Stylistique comparée du français et de l'anglais, Paris, Didier, et Montréal, Beauchemin, 1958, p. 194-197. 
Après s'être livrés à une orgie, ils sombrèrent dans une euphorie semblable à celle que connaissent les « fumeurs » invétérés.

Following a bacchanalian revel, they were dashed in a stage of euphory like the one experienced by deep-rooted « smokers $»$.

Après une orgie bachique, ils furent plongés dans un état d'euphorie semblable à celui que connaissent les fumeurs invétérés.

The psychedelic dreams of the inveterate smoker soon followed their copious libations.

Leurs libations copieuses les plongèrent dans les rêves des fumeurs d'opium.

Indulged in copious potations, they sank into a dreamland of ecstasies.

Après force rasades, ils sombrèrent dans le domaine enchanteur de l'extase.

After many a drink, they sank into a delightful ecstasy.

Après avoir bu plusieurs tasses, ils sombrèrent dans une douce euphorie.

Pour mémoire:

« Ainsi, ils s'aveuglaient eux-mêmes avec l'impalpable et titillante poudre du détail, comme avec du tabac à priser. »

Paul A. Horguelin 